\title{
Discharge estimation in a backwater affected meandering river
}

\author{
H. Hidayat ${ }^{1,2}$, B. Vermeulen ${ }^{1}$, M. G. Sassi ${ }^{1}$, P. J. J. F. Torfs ${ }^{1}$, and A. J. F. Hoitink ${ }^{1,3}$ \\ ${ }^{1}$ Hydrology and Quantitative Water Management Group, Wageningen University, Wageningen, The Netherlands \\ ${ }^{2}$ Research Centre for Limnology, Indonesian Institute of Sciences, Cibinong, Indonesia \\ ${ }^{3}$ Institute for Marine and Atmospheric Research Utrecht, Department of Physical Geography, Utrecht University, \\ Utrecht, The Netherlands
}

Received: 4 March 2011 - Published in Hydrol. Earth Syst. Sci. Discuss.: 9 March 2011

Revised: 10 August 2011 - Accepted: 22 August 2011 - Published: 30 August 2011

\begin{abstract}
Variable effects of backwaters complicate the development of rating curves at hydrometric measurement stations. In areas influenced by backwater, single-parameter rating curve techniques are often inapplicable. To overcome this, several authors have advocated the use of an additional downstream level gauge to estimate the longitudinal surface level gradient, but this is cumbersome in a lowland meandering river with considerable transverse surface level gradients. Recent developments allow river flow to be continuously monitored through velocity measurements with an acoustic Doppler current profiler (H-ADCP), deployed horizontally at a river bank. This approach was adopted to obtain continuous discharge estimates at a cross-section in the River Mahakam at a station located about $300 \mathrm{~km}$ upstream of the river mouth in the Mahakam delta. The discharge station represents an area influenced by variable backwater effects from lakes, tributaries and floodplain ponds, and by tides. We applied both the standard index velocity method and a recently developed methodology to obtain a continuous time-series of discharge from the H-ADCP data. Measurements with a boat-mounted ADCP were used for calibration and validation of the model to translate H-ADCP velocity to discharge. As a comparison with conventional discharge estimation techniques, a stage-discharge relation using Jones formula was developed. The discharge rate at the station exceeded $3250 \mathrm{~m}^{3} \mathrm{~s}^{-1}$. Discharge series from a traditional stage-discharge relation did not capture the overall discharge dynamics, as inferred from H-ADCP data. For a specific river stage, the discharge range could be as high as $2000 \mathrm{~m}^{3} \mathrm{~s}^{-1}$, which is far beyond what could be explained from kinematic wave dynamics. Backwater effects from lakes were shown to be significant, whereas interaction of the river flow with tides may impact discharge variation in
\end{abstract}

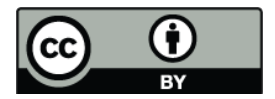

Correspondence to: H. Hidayat (hidayat.hidayat@wur.nl) the fortnightly frequency band. Fortnightly tides cannot easily be isolated from river discharge variation, which features similar periodicities.

\section{Introduction}

Discharge is the phase in the hydrological cycle in which water is confined in channels, allowing for an accurate measurement compared to other hydrological phases (Herschy, 2009). Reliable discharge data is vital in research focusing on a broad range of topics related to water management, including water allocation, navigation, and the prediction of floods and droughts. Also, it is crucial in catchmentscale water balance evaluations. Hydrological studies relying on rainfall-runoff models require continuous discharge series for model calibration and validation (e.g. Beven, 2001; McMillan et al., 2010).

Discharge estimates are conventionally obtained from a rating curve model, using water level data as input, and a limited number of discharge measurements for calibration. Despite a number of techniques available to account for unsteady flow conditions, water agencies often assume an unambiguous relation between stage and discharge. Both steady and unsteady rating curve models are prone to uncertainties, related to interpolation and extrapolation errors and seasonal variations of the state of the vegetation (Di Baldassarre and Montanari, 2009). Changes in the stage-discharge relations frequently occur due to variable backwater effects, rapidly changing discharge, overbank flow, and ponding in areas surrounding the channel (Herschy, 2009). From discharge uncertainty assessment for the River Po, Di Baldassarre and Montanari (2009) showed that the use of a rating curve can lead to an error in discharge estimates averaging $25.6 \%$. In this contribution we show that error in estimates from traditional single gauge rating curves can be even higher, confirming the need for alternative approaches. 
Single-valued rating curves can produce biased discharge estimates, especially in highly dynamic rivers and streams. In terms of the momentum equation, this bias is the result of temporal and spatial acceleration terms, and the pressure gradient term, which all have to be neglected to justify an unambiguous relation between stage and discharge. River waves featuring such unambiguous relation are termed kinematic. When the pressure gradient term is retained, but the acceleration terms can be neglected, the momentum balance appears as a convection-diffusion equation that can be solved to yield a non-inertial wave as a special type of diffusion wave (Yen and Tsai, 2001). Several formulas have been developed aiming to obtain discharge from parameters that can readily be derived from water level time-series. Among these, the Jones formula (Jones, 1916) is the most well-known, in which the surface level gradient term is approximated using the kinematic wave equation. The Jones' formula has been subject to many investigations since its publication (see Schmidt, 2002 and Dottori et al., 2009 for a review). Strictly speaking, it may be more correct to refer to the formula as the JonesThomas formula, as it was Thomas who replaced the spatial derivative term by a temporal derivative term, in order to enable estimating the discharge from at-a-station stage measurements (A. D. Koussis, personal communication, 2011).

Variable backwater is one of the principle factors that cause an ambiguous stage-discharge relation. Backwater from one or several downstream elements such as tributaries, lakes, ponds or dams, complicates rating curve development at hydrometric gauging stations (Petersen-Overleir and Reitan, 2009). Tides superimposed on river discharge can produce subtidal water level variations (Buschman et al., 2009), with periods of a fortnight or longer, which may not immediately be recognized as phenomena controlled by the tidal motion. Potentially, water level setup by river-tide interactions can cause backwater effects beyond the point of tidal extinction (Godin and Martínez, 1994).

Recently, approaches have been developed to account for backwater effects, using a twin gauge approach to obtain estimates of the longitudinal water level gradient. Such ratings are developed based on records of stage at a base gauge and the fall of the water surface between the base gauge and a second gauge downstream (Herschy, 2009). Considering the water level gradient to be a known variable, the terms representing the pressure gradient and spatial acceleration in the momentum equation can be resolved (Dottori et al., 2009). The application of formulas using simultaneous stage measurements was criticised by Koussis (2010). Dottori and Todini (2010) refuted most of the criticism by Koussis (2010), but acknowledged that in lowland areas with a small bed level gradient, the occurring water level gradient can drop below the measuring accuracy of the level gauge. Dottori and Todini (2010) estimate the minimum distance between the gauges to be in between 2000 and $5000 \mathrm{~m}$ when the bed slope is $1 \times 10^{-5}$. Since cross-profiles of the water level are not taken into consideration in one dimensional river hydraulics, neither Koussis (2010) nor Dottori and Todini (2010) considered the drawback that arises from lateral water level gradients, which can be considerable especially in meandering rivers characterised by a high sinuosity. In high-curvature river reaches, level gauges on opposite sides of each of the two cross-section would be needed to infer the longitudinal water surface gradient. We conclude that the twin gauge approach to discharge measurements is suboptimal in lowland meandering rivers, which are most susceptible to backwater effects.

Discharge can be estimated from flow velocity, which bears a much stronger relation to discharge than the water surface. Gordon (1989) was among the first to estimate discharge from a boat-mounted acoustic Doppler current profiler (ADCP), which soon after became a standard means of estimating discharge accurately. ADCP surveys are costly and are carried out merely occasionally. Recent developments allow horizontal profiles of flow velocity to be continuously monitored by a horizontal acoustic Doppler current profiler (H-ADCP). The H-ADCP is typically deployed at a river bank, measuring a horizontal velocity profile across a channel. The acquired data can then be used to estimate discharge, predicting cross-section integrated velocity from the array data of flow velocity.

Several methods are available to convert H-ADCP data to discharge. In the Index Velocity Method (IVM), H-ADCP velocity estimates are averaged and linearly regressed with those obtained from boat-mounted ADCP measurements, then discharge is obtained from the area-velocity relation (Simpson and Bland, 2000; Le Coz et al., 2008). Nihei and Kimizu (2008) adopted a deterministic approach, assimilating H-ADCP data with a two-dimensional model of the velocity distribution over a river cross-section. In the velocity profile method (VPM) described by Le Coz et al. (2008), total discharge is inferred from theoretical vertical velocity profiles, made dimensional with the H-ADCP velocity measurements across the section, extrapolated over the river width. Hoitink et al. (2009) combined elements of the IVM and VPM methods, using a boundary layer model to calculate specific discharge from a point measurement of velocity, and a regression model to relate specific discharge to total discharge. Sassi et al. (2011) elaborated on the work of Hoitink et al. (2009) by embedding a more sophisticated boundary layer model that accounts for side wall effects in the methodology, and letting model coefficients be stage dependent instead of constant. Whereas both Hoitink et al. (2009) and Sassi et al. (2011) focused on tidal rivers, the present contribution presents an $\mathrm{H}-\mathrm{ADCP}$ deployment in a backwater affected inland river.

The remainder of this paper is organized as follows. Section 2 describes the field site and data gathering. Section 3 presents flow structure and the techniques adopted to convert H-ADCP velocity data to total discharge, applying the method by Sassi et al. (2011). Also, traditional rating curve techniques used for comparison are described. Section 4 


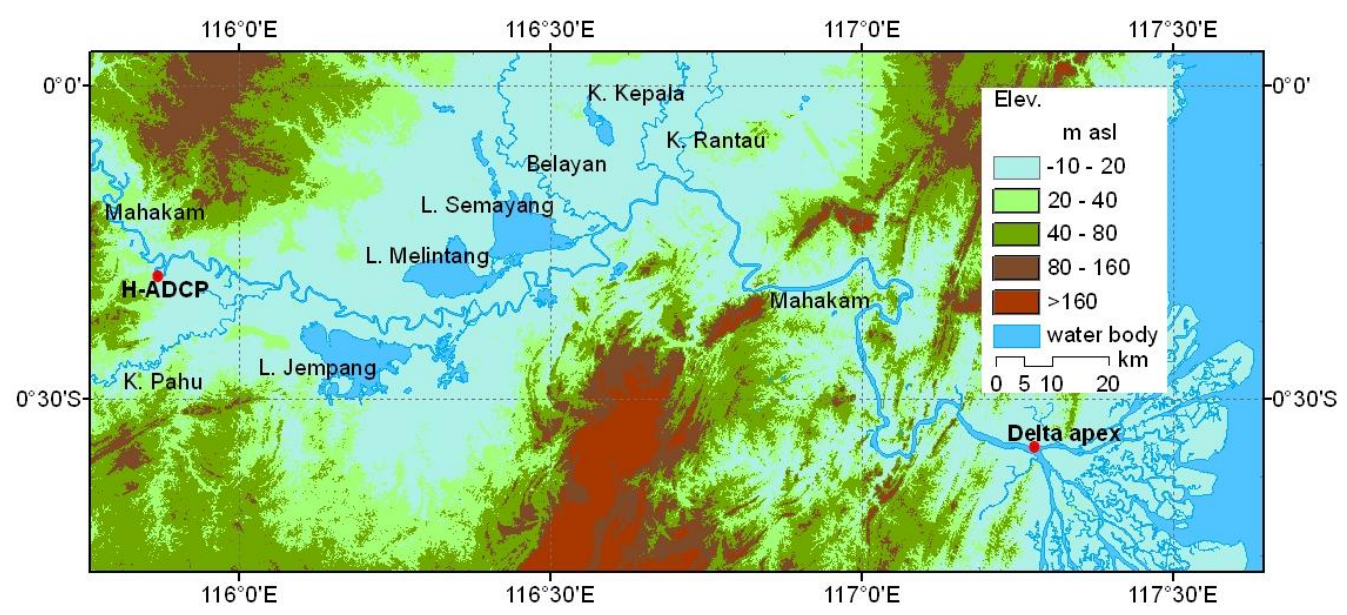

Fig. 1. Location of H-ADCP discharge station in the Mahakam River, plotted on a digital elevation model obtained from Shuttle Radar Topographic Mission (SRTM) data.

presents the results and a discussion and in Sect. 5 conclusions are drawn.

\section{Study area and data gathering}

This study is based on measurements carried out in the River Mahakam, which drains an area of about $77100 \mathrm{~km}^{2}$ in East Kalimantan, Indonesia. The H-ADCP measurement station is located in Melak in the middle Mahakam area about $300 \mathrm{~km}$ from the delta apex (Fig. 1). The middle Mahakam area is an extremely flat tropical lowland with some thirty shallow lakes connected to the Mahakam through small channels. It can be considered a remote, poorly gauged region. A tributary, River Kedang Pahu, meets the Mahakam about $30 \mathrm{~km}$ downstream of Melak. Downstream of the lakes region, the Mahakam is tied to three other main tributaries (River Belayan, Kedang Kepala, and Kedang Rantau) and flows south-eastwards until the discharge is divided over delta distributaries debouching into the Makassar Strait.

The H-ADCP discharge measurement station was operational at a $270 \mathrm{~m}$ wide cross section of the Mahakam river in Melak (Fig. 2) between March 2008 and August 2009. A $600 \mathrm{kHz} \mathrm{H}-\mathrm{ADCP}$ manufactured by RD Instruments was mounted on a solid jetty in the concave side of the river bend. Riverbanks at this particular location are quite steep, leading to a cross-section with a relatively confined flow, except at very high and unusual discharges. The H-ADCP was mounted at about $2.5 \mathrm{~m}$ below the lowest recorded water level and about $2 \mathrm{~m}$ from the bottom. Pitch and roll of the instrument remained relatively constant during the measuring period, amounting to $0.3^{\circ}$ and $0.01^{\circ}$, respectively. The measurement protocol for the $\mathrm{H}-\mathrm{ADCP}$ consisted in $10 \mathrm{~min}$ bursts at $1 \mathrm{~Hz}$ every $30 \mathrm{~min}$.
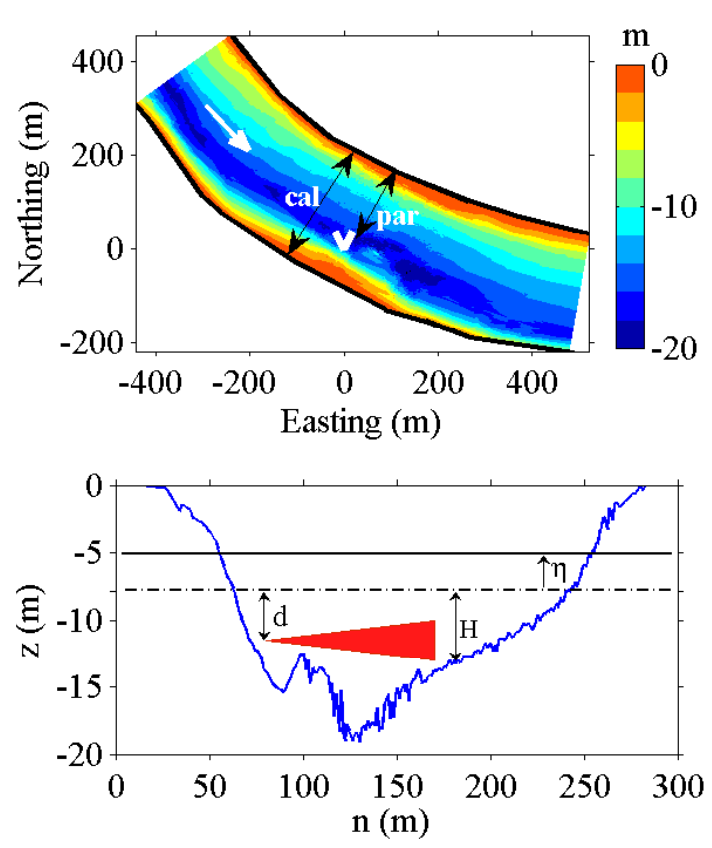

Fig. 2. Top: bathymetry at Melak discharge gauging station. The arrow indicates flow direction, $\mathrm{V}$ indicates the location where the H-ADCP was deployed, double arrows indicate locations of boatmounted ADCP transects. Bottom: channel cross-sectional profile at the station. The shaded area indicates cross-section of the $\mathrm{H}$ $\mathrm{ADCP}$ conical measuring volume, $d$ is the distance of the H-ADCP below the mean water level, $H$ is mean water depth, $\eta$ is water level variation, and $z$ is normal distance from the bed.

The H-ADCP used in this study is a three-beam instrument with angles between beams of $25^{\circ}$ and an acoustic beam width $\phi$ of $1.2^{\circ}$. The H-ADCP was installed at a distance $d=7.9 \mathrm{~m}$ below the mean water level, with the transducer head at $x=74.4 \mathrm{~m}$ from the shore. The lowest recorded water 
level was used as the reference water level. Because the HADCP was deployed looking slightly upward, the H-ADCP measured a volume-averaged velocity at elevation $z_{c}$, which is calculated from:

$z_{c}=\left\{\begin{array}{l}-d+\tan (\theta)(n-x) \text { if } d+\eta>\tan (\phi / 2+\theta)(n-x) \\ -d+\tan (\theta)(n-x)+\Delta z \quad \text { otherwise }\end{array}\right.$

where $\theta$ is pitch, $n$ is cross-channel coordinate, with the origin at the river bank and $\eta$ is water level variation. $\Delta z$ is the level difference between the centroid of the ensonified water area and the central beam axis. This correction accounts for the lowering of the centroid of the ensonified water volume if the main lobe intersects with the water surface at low water (Hoitink et al., 2009).

Conventional boat-mounted ADCP measurements were periodically taken at the cross-section where the H-ADCP was deployed to establish water discharge through the river section. Six surveys were carried out spanning low and high flow conditions. The survey consisted of transects in front of the H-ADCP for determining hydraulic parameters (referred to as "par") and transects carried out about $20 \mathrm{~m}$ upstream to cover the whole river section for calibrating and validating the discharge computation (referred to as "cal" and "val", respectively). Each transect measurement spanned over about two hours. The boat was equipped with a $1.2 \mathrm{MHz}$ RDI Broadband ADCP measuring in mode 12, a DGPS compass and an echosounder. The ADCP measured a single ping ensemble at approximately $1 \mathrm{~Hz}$ with a depth cell size of $0.35 \mathrm{~m}$. Each ping was composed of 6 sub-pings, separated by $0.04 \mathrm{~s}$. The range to the first cell center was $0.865 \mathrm{~m}$. The boat speed ranged between 1 and $3 \mathrm{~m} \mathrm{~s}^{-1}$.

Recently, Moore et al. (2010) found that H-ADCP data can be flawed by the effect of acoustic side lobe reflections from the water surface or from the bed. Figure 3 investigates data quality from a comparison between H-ADCP velocity estimates with corresponding boat-mounted ADCP data (top panel), and profiles of H-ADCP backscatter, averaged over the three beams (bottom panel). The agreement between $\mathrm{H}$ $\mathrm{ADCP}$ and boat-mounted velocity estimates is not as good as reported by Hoitink et al. (2009) and Sassi et al. (2011), which is caused by substantial horizontal velocity shears related to the jetty protruding over $30 \%$ of the river width. Since the sampling volume of the horizontal cells of the $\mathrm{H}$ ADCP do not exactly match with the vertical cells of the boat-mounted ADCP, discrepancies as observed can be expected in a shear flow. In addition, as argued by Hoitink et al. (2009), the quality of the conventional ADCP measurement from a boat that turns may be lower than that of a H-ADCP, explaining the discrepancies in the field near the transducer. The uniformity of the H-ADCP velocity profiles, and the gradual decrease of the H-ADCP backscatter profiles with distance from the transducer, confirm that the H-ADCP velocity estimates are based on reflections from the acoustic

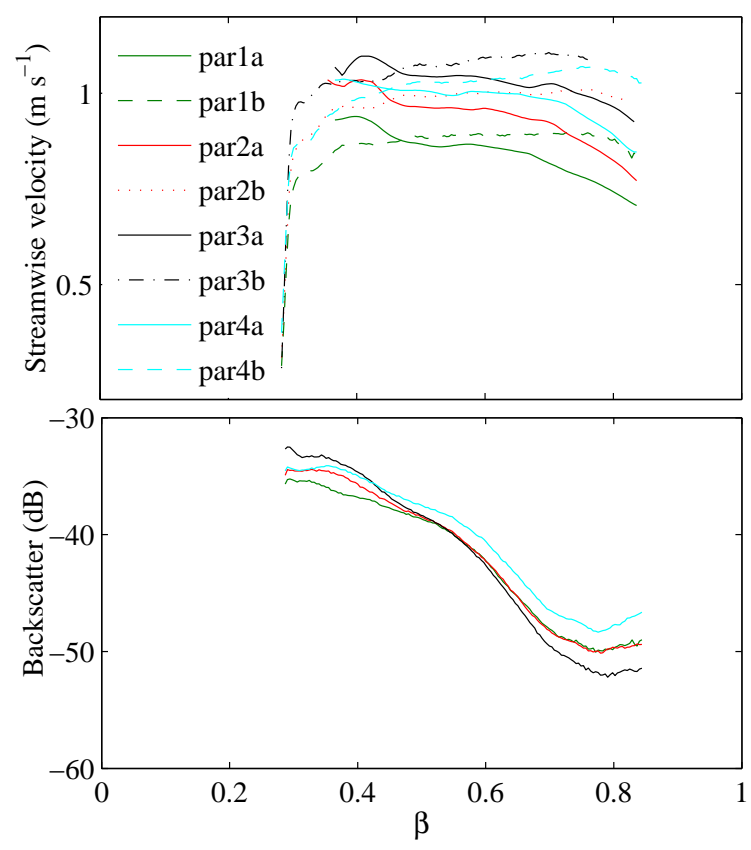

Fig. 3. Top panel: Comparison of streamwise velocity profiles estimated from boat-mounted ADCP measurements (index a) and HADCP data (index b) during the surveys used for parameter assessment. Bottom panel: H-ADCP backscatter profiles, averaged over the three beams, for the surveys corresponding to the top panel.

main lobes. Side lobes would raise the backscatter profile and lead to underestimation of the velocity magnitude, which is not the case.

Depth estimates from the ADCP bottom pings were used to construct a local depth map. The range estimation from the four acoustic beams was corrected for pitch, roll, and heading of the ADCP, and referenced to the mean water level. Bathymetry data were also collected using a single beam echosounder for validation. Water levels were measured using pressure transducers in Melak at the H-ADCP station, in Lake Jempang, and in Muara Kaman at the confluence of River Kedang Rantau with the Mahakam, downstream of the Makaham lakes area.

\section{Methods to estimate discharge}

\subsection{Flow structure}

The design of an appropriate discharge estimation method requires information about the local flow structure, which is discussed in the present section based on the boat-mounted ADCP surveys. The ADCP velocity measurements were projected onto normalized $(\beta, \sigma)$ coordinates. The normalized spanwise coordinate $\beta$ was obtained by normalizing the distance from the bank to the maximum width within that survey. The total width value to normalize $\beta$ is $270 \mathrm{~m}$. The normalized vertical coordinate $\sigma$ was obtained from: 

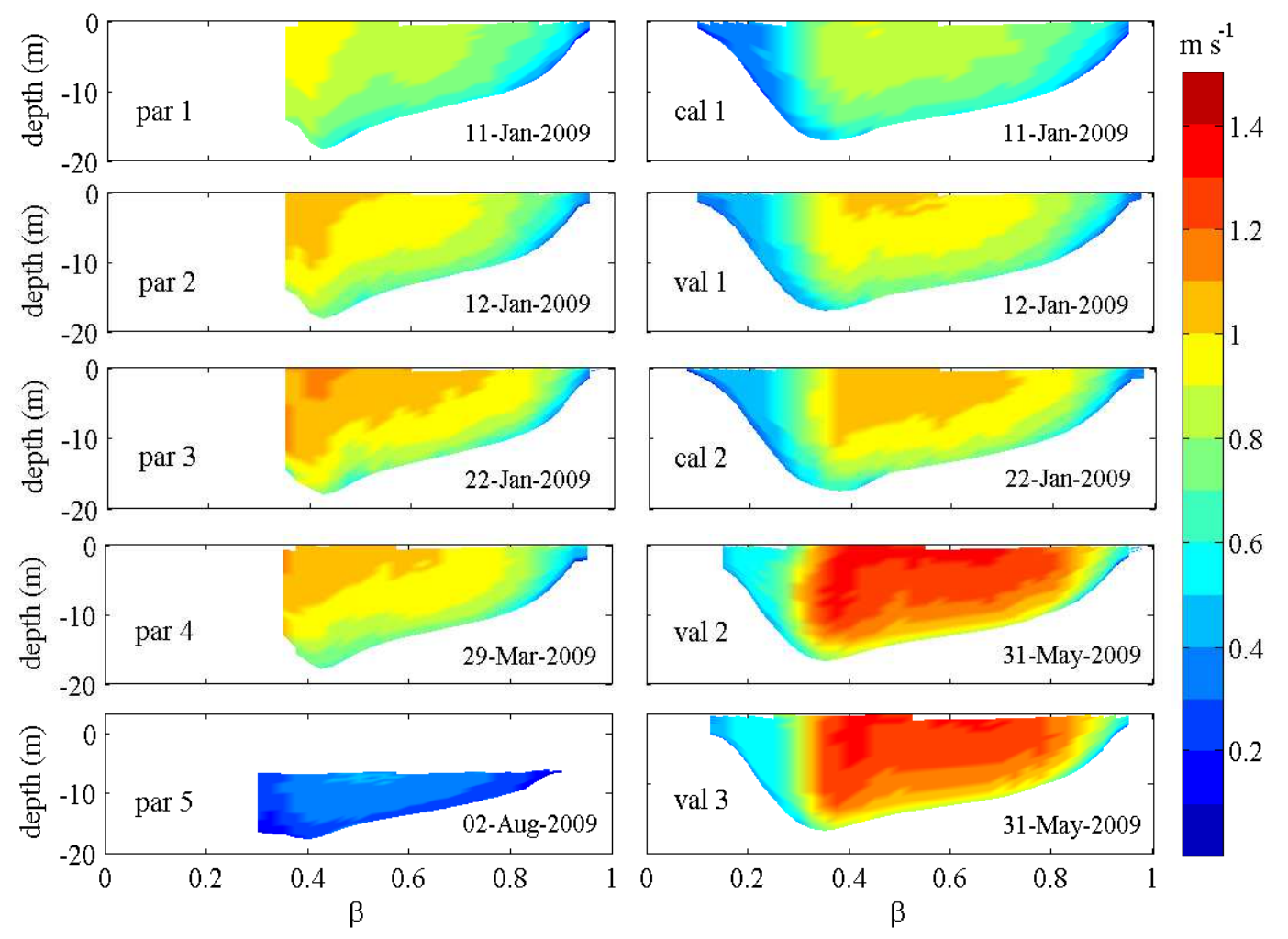

Fig. 4. Streamwise velocity spatial structure over the cross-section during boat-mounted ADCP surveys. Transects labelled "par" were taken in front of the H-ADCP to obtain hydraulic parameters, while the ones labelled "cal" and "val" were taken 20 m upstream to cover the whole channel width for calibration and validation.

$\sigma=\frac{H+z}{H+\eta}$

where $H$ is mean water depth, $z$ is normal distance from the bed. The mesh size of the coordinate was $\Delta \beta=0.025$ and $\Delta \sigma=0.05$. Turbulence fluctuations were removed by taking the mean over the repeated velocity recordings for each grid cell within a survey. Velocity profiles from boat-mounted ADCP measurements were then averaged over depth according to:

$\boldsymbol{U}=\int_{0}^{1} \boldsymbol{u}(\sigma, \beta, t) \mathrm{d} \sigma$

$\boldsymbol{V}=\int_{0}^{1} \boldsymbol{v}(\sigma, \beta, t) \mathrm{d} \sigma$

where $\boldsymbol{u}$ and $\boldsymbol{v}$ are mean velocity components in streamwise and spanwise directions, respectively.

Flow velocity in the Mahakam River varied between moderate and high during the calibration and validation surveys. Figure 4 shows the spatial structure of velocity during each
ADCP survey. Velocity patterns among different surveys show similar spatial characteristics. Relatively low velocity is observed in the upstream area behind the jetty, where the $\mathrm{H}-\mathrm{ADCP}$ was deployed. High velocity is distributed from the middle section toward the opposite bank and decreases to a zone of null velocity at $\beta>0.9$. Due to technical problems, the ADCP transects covering the whole cross section were not taken during the extremely low flow condition. We did navigate the cross-river transect in front of the jetty at low flow. Figure 5 shows the vertical velocity profile obtained from averaging between $\beta=0.35$ and 0.65 , for each survey. Within the latter range for $\beta$, velocity profiles are relatively stable during different stream flow conditions. The vertical velocity profiles are shown to be largely logarithmic, except for a small region near the surface where a velocity dip can be observed, especially during high flow conditions.

We applied the methods described by Sassi et al. (2011) and the IVM to obtain a continuous discharge estimate from $\mathrm{H}$-ADCP data. As a comparison with conventional discharge estimation technique, a stage-discharge relation using Jones formula is developed. 

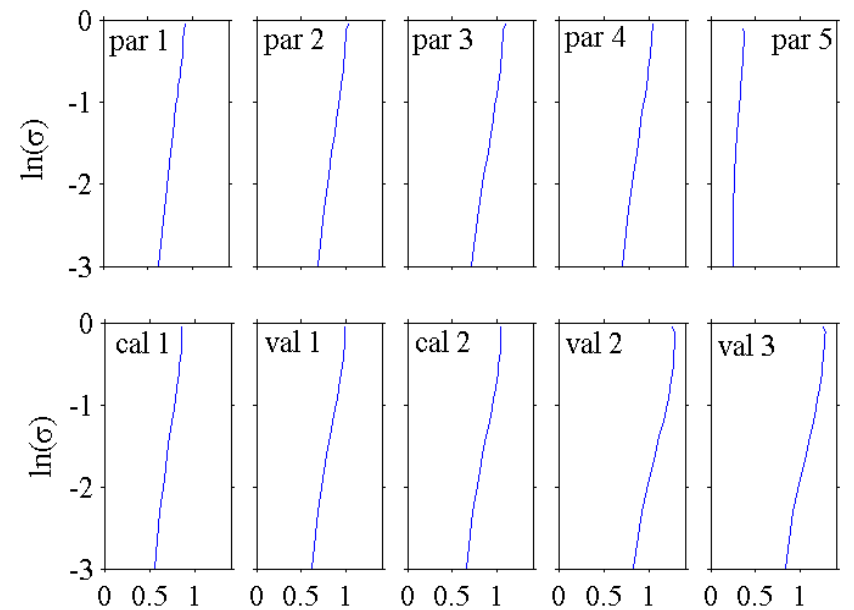

Averaged streamwise velocity $\left(\mathrm{m} \mathrm{s}^{-1}\right)$

Fig. 5. Velocity profiles averaged over the middle part of the river section $(\beta=0.35-0.65)$ during the ADCP surveys.

\subsection{Semi-deterministic semi-stochastic method}

The semi-Deterministic semi-Stochastic Model (DSM) developed by Hoitink et al. (2009) and Sassi et al. (2011) consists of the following parts:

\subsubsection{Deterministic part}

Time-series of single point velocity $\boldsymbol{u}_{c}$, measured at the relative height $\sigma_{c}$, are translated into depth-mean velocity $\boldsymbol{U}$ according to:

$\boldsymbol{U}=F \boldsymbol{u}_{c}$

where

$F=\frac{\ln \left(\frac{H+\eta}{\exp (1+\alpha)}\right)-\ln \left(z_{0}\right)}{\ln \left(\sigma_{c}(H+\eta)\right)+\alpha \ln \left(1-\sigma_{c}\right)-\ln \left(z_{0}\right)}$

Herein, $\alpha$ accounts for sidewall effects that retard the flow near the surface by means of secondary circulations and $z_{0}$ is the apparent roughness length. The value of $\alpha$ is obtained from:

$\alpha=\frac{1}{\sigma_{\max }}-1$

where $\sigma_{\max }$ is the relative height where the maximum velocity occurs. To estimate $\sigma_{\max }$ we closely followed the approach of Sassi et al. (2011) by repeatedly fitting a logaritmic profile starting with the lowermost three ADCP cells, adding successively a velocity cell from the bottom to the top for each fit. $\sigma_{\max }$ is determined from the development of the goodness of fit which decreases once the cell above $\sigma_{\max }$ is included. Figure 6 illustrates that cross-river profiles of $\alpha$ do not show a systematic variation between $0.2<\beta<0.9$.

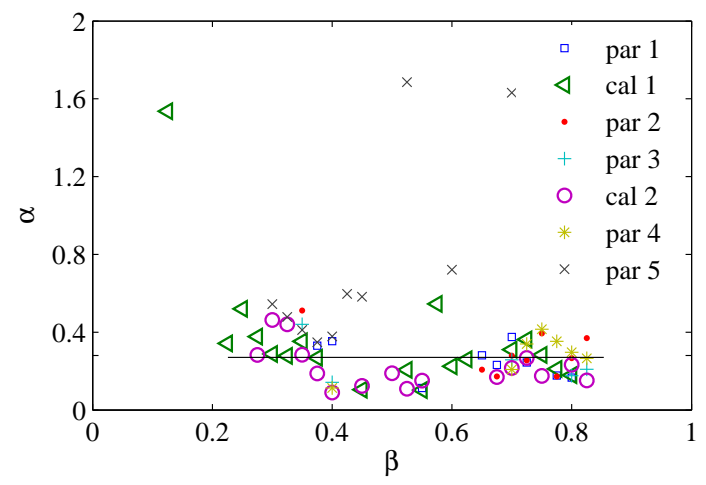

Fig. 6. Profiles of $\alpha$ across the river section for boat-mounted ADCP parameter and calibration surveys. In the conversion model $\alpha=0.28$ is taken for $\beta>0.35$.

We adopt a constant value of $\alpha=0.28$, which results in $\sigma_{\max }=0.78$.

The determination of the effective hydraulic roughness length $z_{0}$ is fundamental in the approaches by both Hoitink et al. (2009) and Sassi et al. (2011). The value of $z_{0}$ is obtained as:

$z_{0}=\frac{H+\eta}{\exp \left(\frac{\kappa \boldsymbol{U}}{\boldsymbol{u}_{*}}+1+\alpha\right)}$

where $\kappa$ is the Von Karman constant and $\boldsymbol{u}_{*}$ is the shear velocity. Values of $\boldsymbol{u}_{*}$ coincide with the slope of the linear regression line of $\boldsymbol{u}(\sigma)$ against $(\ln (\sigma)+1+\alpha+\alpha \ln (1-\sigma)) / \kappa$ (Sassi et al., 2011). Figure 7 shows that values of $z_{0}$ change over width and are consistent at each $\beta$ location for each ADCP surveys in the range $\beta>0.4$. The geometric mean of $z_{0}$ at each $\beta$ location over all boat-mounted transects in front of the H-ADCP (par) were taken for further computation, processing only the $\mathrm{H}-\mathrm{ADCP}$ data in the range $\beta>0.4$.

\subsubsection{Stochastic part}

In the stochastic part of the method, a regression model is developed to translate specific discharge to total discharge, which renders the need for the H-ADCP to cover the full width of the profile superfluous. Specific discharge $\boldsymbol{q}$ is obtained from $\boldsymbol{q}=\boldsymbol{U}(H+\eta)$, where $\boldsymbol{U}$ is depth mean velocity estimates from H-ADCP measurements. The regression model to estimate total discharge $\boldsymbol{Q}$ from $\boldsymbol{q}$, uses an amplification factor $f$ that depends only on the position in the crosssection:

$\boldsymbol{Q}(t)=f(\beta) B \boldsymbol{q}(\beta, t)$

where $B$ is the river width, $f(\beta)$ is obtained from the total discharge of each boat-mounted ADCP "cal" survey divided by the product $B \boldsymbol{q}$ from the corresponding "par" surveys. Hoitink et al. (2009) discusses the independence of 


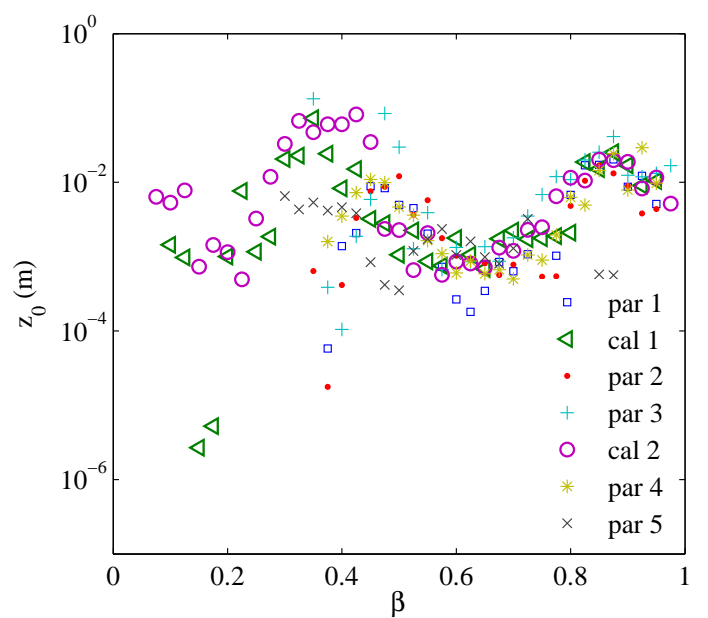

Fig. 7. Cross-river profiles of $z_{0}$ for boat-mounted ADCP parameter and calibration surveys.

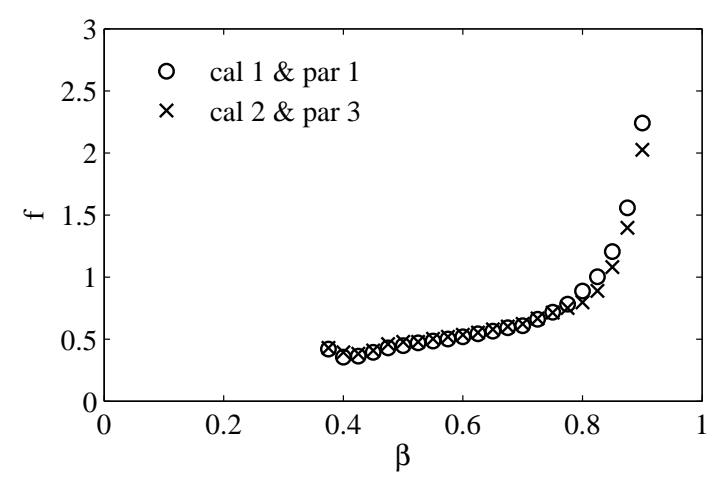

Fig. 8. Amplification factor $f$ obtained for quasi-simultaneous boat-mounted ADCP parameter and calibration surveys.

$f(\beta)$ from time and the rationale to include this constant amplification factor in the linear model to estimate $Q$. Profiles of $f$ remain constant up to $\beta=0.8$ during the two calibration surveys (Fig. 8), which shows how $\boldsymbol{q}$ times $B$ relates to $\boldsymbol{Q}$. From the two $f$ profiles, the mean value of $f$ at each beta location was taken and multiplied by $q$ at a single beta position to compute discharge. Hence, from each of the discrete ranges to the H-ADCP velocity cells, a time-series of total discharge was obtained. Time-series of $\boldsymbol{Q}$ were finally obtained by averaging up to $\beta=0.7$ yielding accurate discharge estimates at any moment in time.

\subsection{Index velocity method}

We also estimated discharge from the H-ADCP data based on the IVM approach (Le Coz et al., 2008). We compute discharge by regressing the H-ADCP index velocity with crosssection averaged velocity, yielding discharge after multiplying it with the cross-section area. We used the more representative and accurate part of the HADCP velocity profile data

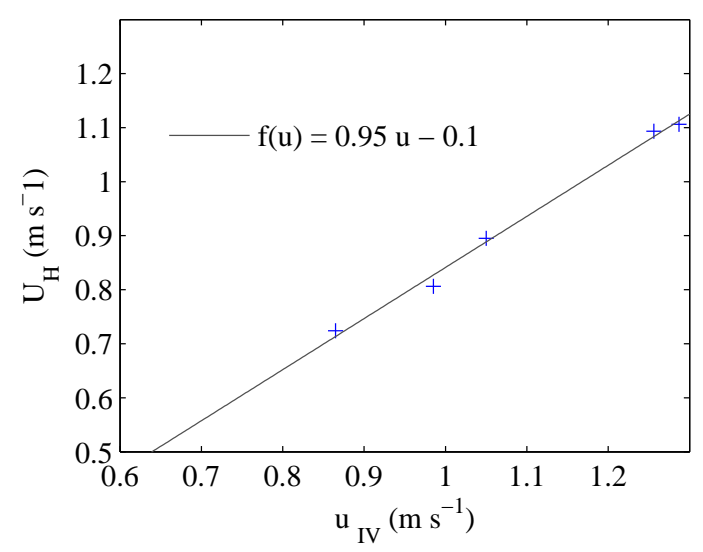

Fig. 9. IVM rating fitted by linear regression over five boat surveys covering the whole channel width.

from $\beta=0.5$ to 0.7 for computing the index velocity. The IVM discharge was computed as:

$\boldsymbol{Q}_{\mathrm{IVM}}=f(\boldsymbol{u}) A$

where $\boldsymbol{u}$ is the index velocity and $A$ is river cross sectional area calculated from the bathymetry profile and the measured water level. The reference mean velocity $\boldsymbol{U}_{\boldsymbol{H}}$ at the H-ADCP section is obtained from: $\boldsymbol{U}_{\boldsymbol{H}}=\boldsymbol{Q}_{\text {ref }} / A$, herein $\boldsymbol{Q}_{\text {ref }}$ is the reference discharge measured by ADCP. The linear regression over five ADCP surveys covering the whole channel cross section yielded $f(\boldsymbol{u})=0.95 \boldsymbol{u}-0.1$ (Fig. 9).

\subsection{Stage-discharge relation}

To investigate the degree in which discharge at Melak station can be captured by a rating curve, Jones' formula was applied, which reads:

$\boldsymbol{Q}=\boldsymbol{Q}_{\mathrm{kin}}\left\{1+\frac{1}{\boldsymbol{c} S_{0}} \frac{\partial h}{\partial t}\right\}^{1 / 2}$

where $\boldsymbol{Q}_{\text {kin }}$ is the kinematic or equilibrium discharge, $\boldsymbol{c}$ is the wave celerity, $S_{0}$ is the bed slope, and $\partial h / \partial t$ is the rate of water level change in time $t$ all measured at the same location (Petersen-Overleir, 2006). The celerity $c$ was estimated from $c=\frac{d Q}{d A}=B^{-1} \frac{d Q}{d h}$ (Henderson, 1966) based on the steady flow rating curve obtained for Melak. Herein, $A$ is river cross sectional area and $B$ is river width. The bed slope of $10^{-4}$ was estimated from the Mahakam River bed level profile derived from SRTM data by van Gerven and Hoitink (2009). $\boldsymbol{Q}_{\text {kin }}$ was calculated using the Manning formula:

$\boldsymbol{Q}_{\text {kin }}=\frac{1}{n} S_{0}^{1 / 2} A R^{2 / 3}$

where $n$ is Manning roughness coefficient and $R$ is hydraulic radius obtained from the ratio between $A$ and the wetted 
Table 1. Evaluation of channel conditions at Melak station to estimate the Manning coefficient.

\begin{tabular}{ll}
\hline Factor (index) & Description (value) \\
\hline Additive factors & \\
\hline - Material involved $\left(n_{0}\right)$ & Earth $(0.02)$ \\
- Degree of irregularity $\left(n_{1}\right)$ & Minor $(0.005)$ \\
- Var. in location of thalweg $\left(n_{2}\right)$ & Gradual $(0.00)$ \\
- Effect of obstruction $\left(n_{3}\right)$ & Negligible $(0.00)$ \\
- Riparian vegetation $\left(n_{4}\right)$ & Medium $(0.01)$ \\
\hline Multiplicative factors & \\
\hline - Degree of meandering $(m)$ & Appreciable $(1.15)$ \\
\hline$n=\left(n_{0}+n_{1}+n_{2}+n_{3}+n_{4}\right) m=0.04025$ & \\
\hline
\end{tabular}

perimeter of the river cross-section. The Manning coefficient was estimated based on an evaluation of the river geometry and composition, following a standard empirical technique provided by Gore (2006). The details of channel evaluation to determine $n$ are presented in Table 1 .

We used the rating curve discharge estimate from Eq. (11) in most of the discussion in Sect. 4. Equation (12), however, is used with the assumption that the river reach (Fig. 2, top panel) has a uniform channel geometry. The presence of the jetty and boats resulted in irregularity in the channel cross-section (Fig. 2, bottom panel) locally at the station. In the original version of the Jones formula, the discharge taken from the currently available steady flow rating curve $\left(Q_{0}\right)$ is used instead of using Eq. (12). For a comparison, we also computed discharge using the Jones' formula based on $Q_{0}$.

\section{Results and discussion}

Table 2 shows the validation results. Discharge estimates obtained by applying the method by Sassi et al. (2011) and IVM differed less than $5 \%$ from the accurate estimates obtained from the boat surveys. Figure 10 shows time-series of the absolute and relative difference between $Q_{\mathrm{DSM}}$ and $Q_{\text {IVM }}$, which indicate that the validation results represent the medium to high flows well. During low flows, $Q_{\text {DSM }}$ and $Q_{\text {IVM }}$ can deviate much more, both in a relative and in an absolute sense. Unfortunately, a planned validation survey during the low flow condition was cancelled due to technical problems, which could have shed more light on the validity of the low-flow discharge estimates. Regarding high flows, the larger difference between $Q_{\mathrm{DSM}}$ and $Q_{\mathrm{IVM}}$ could be due to the fact that the H-ADCP is monitoring flow at a relative depth that changes with the river stage, which challenges the constancy of the conversion factor to calculate discharge from the index velocity. The IVM is heavily dependent on the degree in which the velocity measurements within the
Table 2. Results of the three validation surveys of the DSM and the IVM methods. $Q_{\mathrm{BS}}$ denotes the discharge calculated from the boat survey, which can be considered truth.

\begin{tabular}{lccccc}
\hline Val. & $Q_{\mathrm{BS}}$ & $Q_{\mathrm{DSM}}$ & $Q_{\mathrm{IVM}}$ & $Q_{\mathrm{DSM}} / Q_{\mathrm{BS}}$ & $Q_{\mathrm{IVM}} / Q_{\mathrm{BS}}$ \\
\hline 1 & 1823 & 1875 & 1889 & 1.03 & 1.04 \\
2 & 2438 & 2439 & 2465 & 1.00 & 1.01 \\
3 & 2387 & 2417 & 2382 & 1.01 & 1.00 \\
\hline
\end{tabular}

H-ADCP range unambiguously covary with the cross-section averaged velocity and on the degree in which the calibration surveys cover extreme conditions. The obtained results highlight the merits of applying the more elaborate procedure advocated by Hoitink et al. (2009) and Sassi et al. (2011) particularly in a remote poorly-gauged area. Compared to the IVM, the DSM is more physically based, which provides a better resilience to cope with a lack of discharge measurements during high flows and low flows. Even in the case of an equal performance, as established from a small number of validation surveys in our study, the DSM is to be preferred because the IVM can be right for the wrong reasons. The IVM is only to be preferred over the DSM when calibration data cover the full range of conditions and there are no inertial effects, which create a time lag between local flow velocity and cross-section averaged flow velocity.

H-ADCP measurements at Melak station revealed a complex stage-discharge relation that was highly hysteretic (Fig. 11). Hysteresis is generally related to flood wave propagation affected by transient flow. For the same water level, discharge is typically higher than average during rising stage and lower than average during falling stage, resulting in distinctive loops in stage-discharge relations (Petersen-Overleir, 2006). Backwater effects that cannot be isolated completely from nonlinear wave effects complicate this relation. Figure 12 shows that variable backwater effects were likely to occur within the hysteresis loop. At Melak station, the range of discharges that can occur for a specific stage can span over more than $2000 \mathrm{~m}^{3} \mathrm{~s}^{-1}$, which is exceptionally large in comparison with the maximum discharge of $3250 \mathrm{~m}^{3} \mathrm{~s}^{-1}$ from the DSM. Such variation can be considered far beyond the rising stage and falling stage explanation. Compared to standard rating curves for different hydraulic conditions (Herschy, 2009), the stage-discharge relation in Fig. 11 will reflect the presence of variable backwater effects, looping due to changing discharge, and multiple looping due to overbank flow and ponding. Radar images showed vast areas in the Mahakam Lakes Region to become inundated during high flows (Hidayat et al., 2011). Part of the complexity in the stage-discharge relation can be explained from the subharmonics generated by river-tide interactions (Buschman et al., 2009). It is striking that tidal influence can reach the site, which is located $300 \mathrm{~km}$ upstream of the river mouth in the 


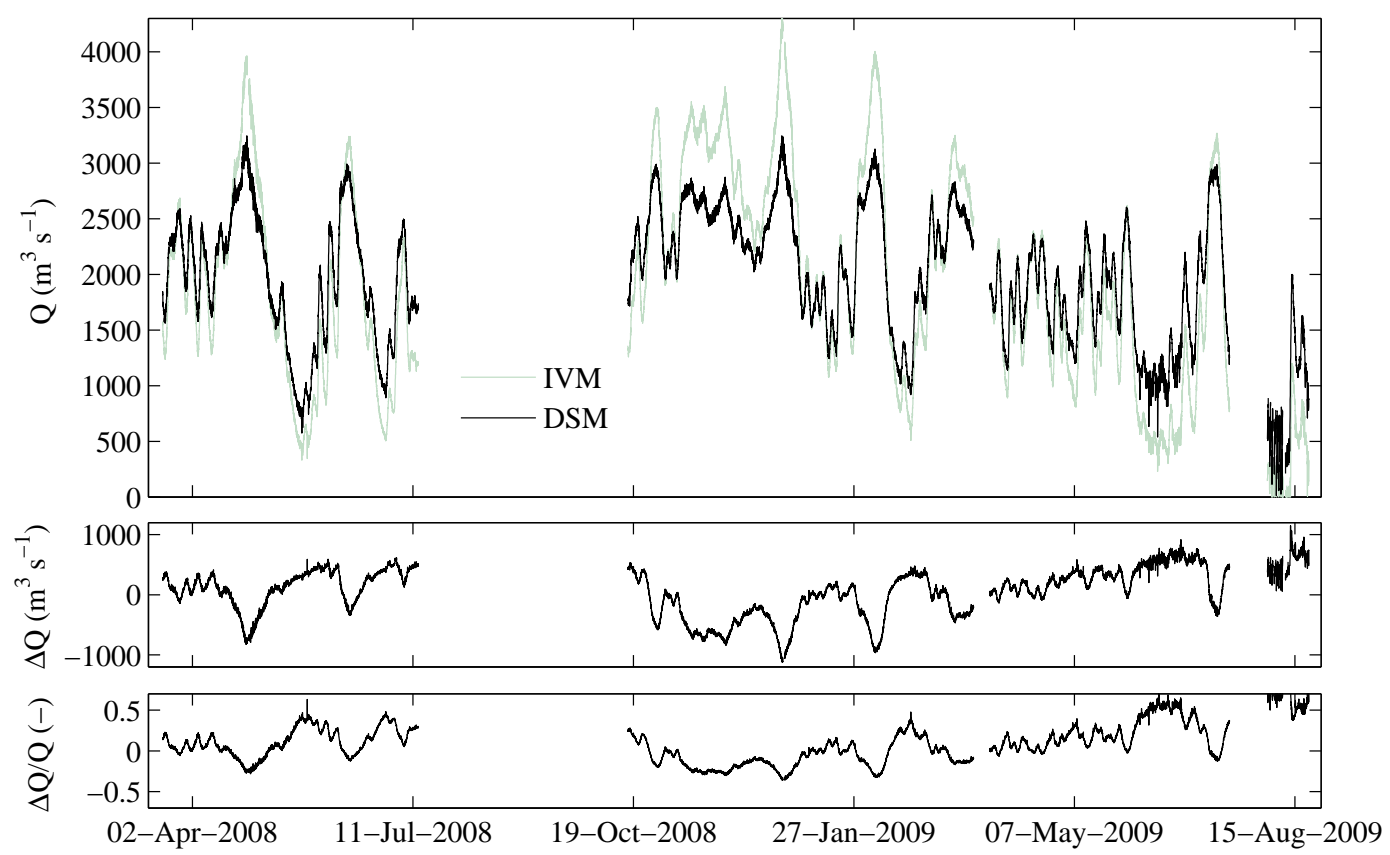

Fig. 10. Continuous series of discharge estimates derived from H-ADCP data with the DSM and the IVM. Central and bottom panels offer a comparison between DSM and the IVM to convert H-ADCP data to discharge, where $\Delta Q=Q_{\mathrm{DSM}}-Q_{\mathrm{IVM}}$.

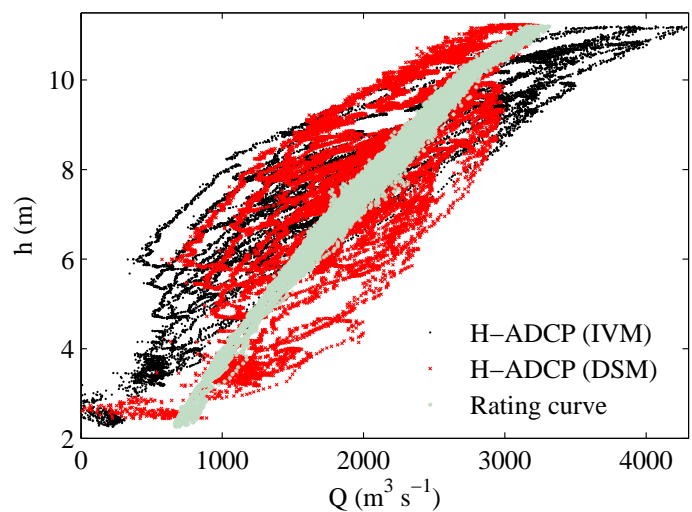

Fig. 11. Water stage and discharge estimates at Melak station, obtained from a rating curve (Jones' formula) and from H-ADCP measurements. Water stage is with respect to the position of a pressure gauge about $9 \mathrm{~m}$ from the deepest part of the river cross-section.

Mahakam delta. At low discharges in August 2009, the tidal signal is clearly visible in the discharge series. Due to the flat terrain of the middle and lower Mahakam, tidal energy propagates up to the Mahakam lakes area, where much of the tidal energy is dissipated. Subharmonics such as the MSf, an oceanographic term for the fortnightly constituent of the tide created by nonlinear interaction of the tides induced by the Moon and the Sun with the river discharge, may extend beyond the lakes region. However, this effect cannot be readily isolated from river discharge variation as discharge variation features fortnightly variation both in the presence and in absence of a tidal influence.

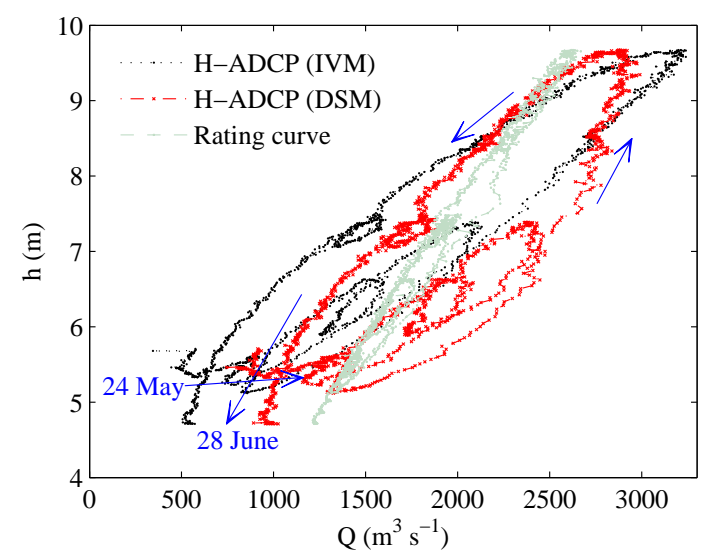

Fig. 12. Water stage versus discharge for the period between 24 May-28 June 2008. Multiple loops and discharge oscillations indicate variable backwater effects also occurred within the hysteresis loop.

The wide loops in the stage-dischage plot are the result of the geographical complexity of the region where Melak station is located, experiencing a flashy discharge from upstream and backwater effects from downstream. The flashy discharge regime relates to high rainfall rates in large parts of the catchment upstream of Melak, which dominates the moderating effect of the rain forest. The backwater effects are caused both by the lakes and a number of tributaries, all affecting the water level profile. Lake emptying and filling processes contribute to retarding and accelerating the river flow 

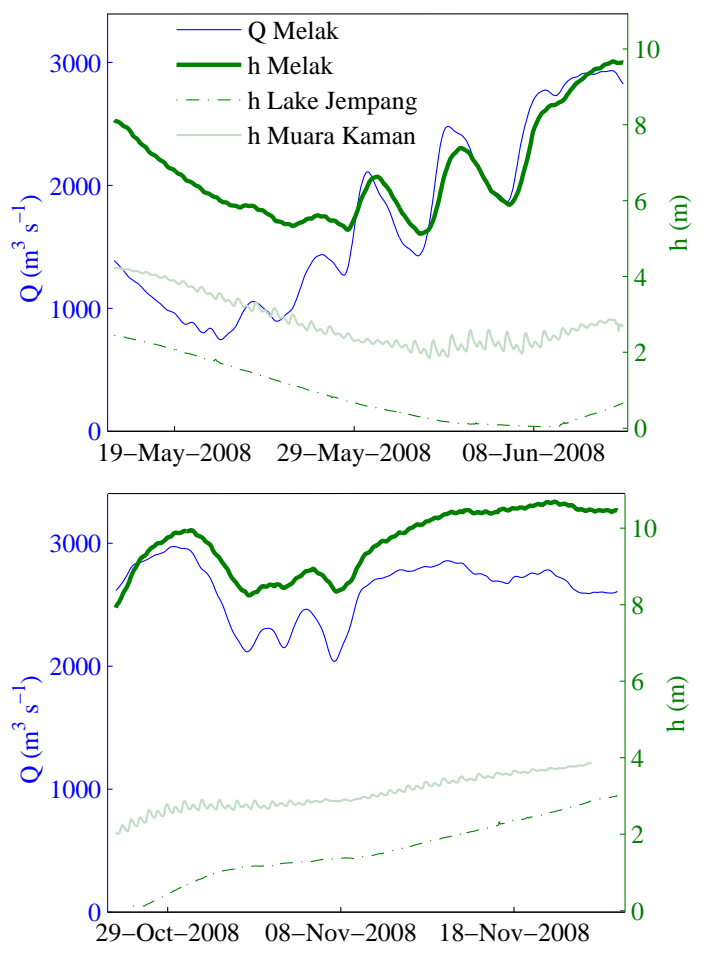

Fig. 13. Water stage and discharge during lake emptying (top) and during lake filling (bottom). Muara Kaman, where the tidal signal was observed during most of the measurement period, is located downstream of the Mahakam lakes area about $170 \mathrm{~km}$ from Melak.

velocity. Figure 13 illustrates the lake emptying and lake filling influencing water levels and discharge upstream. At the start of lake emptying, when the lake level was still high, water stage in Melak was relatively high for a relatively low discharge. When the lake level dropped, the backwater effect was reduced and discharge increased while water stage kept decreasing until the point that discharge was sufficiently high to make water stage follow the trend in the discharge timeseries. The opposite mechanism took place during lake filling as shown in Fig. 13 (bottom panel). Water stage records downstream of the Mahakam lake area (Muara Kaman) indicate that some peaks of water level were shaved by the lake filling and emptying mechanism.

The discharge obtained from the stage-discharge relation using Jones formula is merely a rough estimate of discharge at Melak station, indicating the range of discharge variation. It did not capture the detailed discharge dynamics as revealed by the H-ADCP measurements. This can be related to a wide variety of reasons. The Froude number takes a value around 0.01 , which likely indicates the inertial term in the momentum equation to be negligible. A non-dimensional version of the St. Venant equations directly shows that the inertial terms drop out for small values of the Froude number (Pearson, 1989). The key assumption used to derive the Jones formula is the applicability of the kinematic wave equation to deal

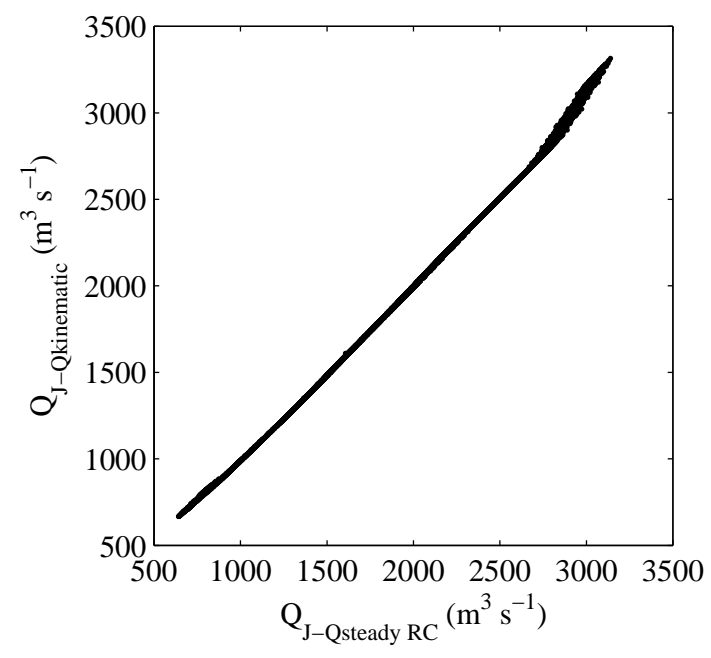

Fig. 14. Comparison of discharge estimates obtained using the Jones formula based on $Q_{\text {kin }}$ (uniform channel geometry assumption) and those based on $Q_{0}$ (discharge taken from the steady flow rating curve $\left.Q_{0}=125.98 \times(h+1.5)^{1.256}\right)$ for the whole observation period. The small deviation confirms that the two approaches yield similar results. Only during peak discharges, the use of $Q_{0}$ instead of $Q_{\text {kin }}$ can result in slightly different rating curve-based estimates of the discharge.

with the surface gradient term in the non-inertial wave equation. Although this approach can be successful under certain bed slope and flow conditions (Pearson, 1989; Perumal et al, 2004; Dottori et al., 2009), the kinematic wave equation cannot capture discharge dynamics in backwater affected river reaches (e.g., Tsai, 2005). The stage-discharge relation is only expected to be applicable if the channel geometry is uniform. The top panel in Fig. 2 shows there is some irregularity in the cross-section, related to the low flow velocities beneath the jetty. Therefore, the complexity of the stage-discharge plot can be partly explained from the non-uniformity of the channel geometry. Figure 14 shows the comparison of discharge estimates obtained using the Jones formula based on $Q_{\text {kin }}$ (uniform channel geometry assumption) and those based on $Q_{0}$ (discharge taken from the steady flow rating curve). During peak discharges, the use of $Q_{0}$ instead of $Q_{\text {kin }}$ can result in slightly different rating curve-based estimates of the discharge. Out-of-bank spills and return flows from flood plains occurring in the study area during the period of flood peak could also be among possible reasons for the failure of the Jones formula to adequately predict flood dynamics. The Jones formula is just one of a series of formulas available to predict discharge from time-series of a single level gauge (Henderson, 1966; Di Silvio, 1969; Fread, 1975; Lamberti and Pilati, 1990; Perumal and Ranga Raju, 1999), all aiming to improve the original Jones' formula. Dottori et al. (2009) explicitly mentions that they are best applicable when flow conditions are quasi kinematic. Backwater effects render the kinematic wave assumption invalid, hence none 
of these approaches will be capable of reproducing the wide loops occurring at Melak station, which underlines the importance of monitoring additional information besides stage at a single section. Considering the ease of deployment of $\mathrm{H}$-ADCPs, they offer a promising alternative to measure discharge.

\section{Conclusions}

Flow measurements using a $600 \mathrm{kHz}$ H-ADCP were carried out at a $300 \mathrm{~m}$ wide cross section of the Mahakam River in Melak, $40 \mathrm{~km}$ upstream of the Mahakam lakes area. Conventional boat-mounted ADCP measurements were periodically taken to establish water discharge through the cross section. We followed a recently developed semi-deterministic, semi-stochastic method (DSM) to convert the H-ADCP to discharge, and compared the results with those obtained from the index-velocity method (IVM) and a rating curve model. The DSM method was found to be comparable with the IVM, the difference with discharge estimates from the boat-mounted ADCP surveys was less than $5 \%$ based on three validation surveys. The continuous time-series of discharge showed that the validation data were representative for medium to high flows. A stage-discharge model based on Jones's formula captured only a small portion of the discharge dynamics, which was attributed to the invalidity of the kinematic wave assumption due to backwater effects. A discharge range of about $2000 \mathrm{~m}^{3} \mathrm{~s}^{-1}$ was established for a particular stage in the recorded discharge series, which is about $60 \%$ of the peak discharge and therefore exceptionally large. The large range of discharge occurring for a given stage was attributed to multiple backwater effects from lakes and tributaries, floodplain impacts and effects of river-tide interaction, which generate subharmonics that cannot readily be isolated from river discharge oscillations.

Acknowledgements. This research has been supported by the Netherlands organisation for scientific research, under grant number WT 76-268. The help from Fajar Setiawan and Unggul Handoko (LIPI - Research Centre for Limnology) and David Vermaas (Wageningen University) in data collection is gratefully acknowledged. The authors appreciate comments and suggestions from the three reviewers that helped improve the manuscript.

Edited by: G. Di Baldassarre

\section{References}

Beven, K. J.: Rainfall-runoff modelling: the primer, John Wiley \& Sons, Chichester, England, 2001.

Buschman, F. A., Hoitink, A. J. F., van der Vegt, M., and Hoekstra, P.: Subtidal water level variation controlled by river flow and tides, Water Resour. Res, 45, 1-12, doi:10.1029/2009WR008167, 2009.
Di Baldassarre, G. and Montanari, A.: Uncertainty in river discharge observations: a quantitative analysis, Hydrol. Earth Syst. Sci., 13, 913-921, doi:10.5194/hess-13-913-2009, 2009.

Di Silvio, G.: Flood wave modifications along prismatic channels, J. Hydraul. Div. ASCE, 95, 1589-1614, 1969.

Dottori, F. and Todini, E.: Reply to Comment on "A dynamic rating curve approach to indirect discharge measurement by Dottori et al. (2009)" by Koussis (2009), Hydrol. Earth Syst. Sci., 14, 1099-1107, doi:10.5194/hess-14-1099-2010, 2010.

Dottori, F., Martina, M. L. V., and Todini, E.: A dynamic rating curve approach to indirect discharge measurement, Hydrol. Earth Syst. Sci., 13, 847-863, doi:10.5194/hess-13-847-2009, 2009.

Fread, D. L.: Computation of stage-discharge relationship affected by unsteady flow, Water Resour. Bull., 12, 429-442, 1975.

Godin, G. and Martínez, A.: Numerical experiments to investigate the effects of quadratic friction on the propagation of tides in a channel, Cont. Shelf Res., 14, 723-748, 1994.

Gordon, R. L.: Acoustic measurement of river discharge, J. Hydraul. Eng., 115, 925-936, 1989.

Gore, J. A.: Methods in Stream Ecology, chap. Discharge Measurements and Streamflow Analysis, Academic Press, 51-77, 2006.

Henderson, F. M.: Open channel flow, Prentice Hall, 544 pp., 1966.

Herschy, R. W.: Streamflow Measurement, Taylor \& Francis, London and New York, 3rd Edn., 2009.

Hidayat, Hoekman, D. H., Vissers, M. A. M., and Hoitink, A. J. F.: Combining ALOS-PALSAR imagery with field water level measurements for flood mapping of a tropical floodplain, Proceedings of the International Symposium on LIDAR and Radar Mapping: Technologies and Applications, Nanjing, China, in press, 2011.

Hoitink, A. J. F., Buschman, F. A., and Vermeulen, B.: Continuous measurements of discharge from a horizontal acoustic Doppler current profiler in a tidal river, Water Resour. Res, 45, 1-13, doi:10.1029/2009WR007791, 2009.

Jones, B. E.: A method of correcting river discharge for a changing stage, US Geological Survey Water Supply Paper, 375-E, 117$130,1916$.

Koussis, A. D.: Comment on "A praxis-oriented perspective of streamflow inference from stage observations - the method of Dottori et al. (2009) and the alternative of the Jones Formula, with the kinematic wave celerity computed on the looped rating curve" by Koussis (2009), Hydrol. Earth Syst. Sci., 14, 10931097, doi:10.5194/hess-14-1093-2010, 2010.

Lamberti, P. and Pilati, S.: Quasi-kinematic flood wave propagation, Meccanica, 25, 107-114, 1990.

Le Coz, J., Pierrefeu, G., and Paquier, A.: Evaluation of river discharges monitored by a fixed side-looking Doppler profiler, Water Resour. Res., 44, 1-13, doi:10.1029/2008WR006967, 2008.

McMillan, H., Freer, J., Pappenberger, F., Krueger, T., and Clark, M.: Impacts of uncertain river flow data on rainfall-runoff model calibration and discharge predictions, Hydrol. Process., 24, 1270-1284, doi:10.1002/hyp.7587, 2010.

Moore, S. A., Le Coz, J., Hurther, D., and Paquier, A.: Backscattered intensity profiles from horizontal acoustic Doppler current profilers, in River Flow 2010, Bundesanstalt fur Wasserbau, Braunschweig, Germany, 1693-1700, 2010.

Nihei, Y. and Kimizu, A.: A new monitoring system for river discharge with horizontal acoustic Doppler current profiler measurements and river flow simulation, Water Resour. Res., 44, 1- 
15, doi:10.1029/2008WR006970, 2008.

Pearson, C. P.: One-dimensional flow over a plane: Criteria for kinematic wave modelling, J. Hydrol., 111, 39-48, 1989.

Perumal, M. and Ranga Raju, K. G.: Approximate convectiondiffusion equations, J. Hydrol. Eng., 4, 160-164, 1999.

Perumal, M., Shrestha, K. B., and Chaube, U. C.: Reproduction of Hysteresis in Rating Curves, J. Hydrol. Eng.-ASCE, 130, 870878, 2004.

Petersen-Overleir, A.: Modelling stage-discharge relationships affected by hysteresis using the Jones formula and nonlinear regression, Hydrol. Sci. J., 51, 365-388, 2006.

Petersen-Overleir, A. and Reitan, T.: Bayesian analysis of stage-fall-discharge models for gauging stations affected by variable backwater, Hydrol. Process., 23, 3057-3074, doi:10.1002/hyp.7417, 2009.

Sassi, M. G., Hoitink, A. J. F., Vermeulen, B., and Hidayat: Discharge estimation from $\mathrm{H}-\mathrm{ADCP}$ measurements in a tidal river subject to sidewall effects and a mobile bed, Water Resour. Res., 47, W06504, 1-14, doi:10.1029/2010WR009972, 2011.
Schmidt, A. R.: Analysis of stage-discharge relations for openchannel flows and their associated uncertainties, PhD thesis,University of Illinois, available at: https://netfiles.uiuc.edu/ aschmidt/www/ARS_Thesis/ARS_Thesis.htm (last access: 9 August 2011), 2002.

Simpson, M. R. and Bland, R.: Methods for accurate estimation of net discharge in a tidal channel, IEEE J. Oceanic Eng, 25, 437445, 2000.

Tsai, C. W.: Flood routing in mild-sloped rivers - wave characteristics and downstream backwater effect, J. Hydrol., 308, 151-167, doi:10.1016/j.jhydrol.2004.10.027, 2005.

van Gerven, L. P. A. and Hoitink, A. J. F.: Analysis of river planform geometry with wavelets: application to the Mahakam River reveals geographical zoning, in: Proceedings of RCEM, 2009.

Yen, B. C. and Tsai, C. W. S.: On noninertia wave versus diffusion wave in flood routing, J. Hydrol., 244, 97-104, 2001. 